\title{
History of Resuscitated Cardiac Arrest
}

National Cancer Institute

\section{Source}

National Cancer Institute. History of Resuscitated Cardiac Arrest. NCI Thesaurus. Code C66927.

An event in the personal medical histroy of cardiac arrest that is reversed, usually by CPR and/or defibrillation or cardioversion, or cardiac pacing. 